\title{
Preliminary safety analyses in the high-level radioactive waste site selection procedure in Germany
}

\author{
Eva-Maria Hoyer, Elco Luijendijk, Paulina Müller, Phillip Kreye, Florian Panitz, Dennis Gawletta, and \\ Wolfram Rühaak \\ BGE mbH - Bundesgesellschaft für Endlagerung, Federal Company for Radioactive Waste Disposal, 31224 Peine, Germany \\ Correspondence: Eva-Maria Hoyer (eva-maria.hoyer@bge.de)
}

Received: 30 June 2021 - Revised: 2 September 2021 - Accepted: 7 September 2021 - Published: 13 October 2021

\begin{abstract}
The Federal Company for Radioactive Waste Disposal (BGE) is responsible for the search for a site with the best possible safety for the disposal of high-level radioactive waste in Germany. The site selection procedure is regulated in a law that was adopted by the German Federal Parliament (Repository Site Selection Act - StandAG, 2017, last updated 2020) and aims to be a participatory, transparent, learning, and self-questioning process based on scientific expertise. The first step of the first phase of the site selection procedure was completed in September 2020 and resulted in the identification of sub-areas that give reason to expect favorable geological conditions for the long-term storage of nuclear waste in the subsurface. These sub-areas cover approximately $54 \%$ of Germany and are located in three different host rocks: rock salt - halite, claystone, and crystalline rock. The challenge for the next step is to find suitable siting regions within the previously determined sub-areas that are then considered further in the next phase of the site selection procedure. In the following, the methodology of the so-called representative preliminary safety analyses is described, which constitute one of the tools to identify siting regions, and some first insight on how they are planned to be implemented in practice is given.
\end{abstract}

\section{Introduction}

The safe storage of nuclear waste is an important societal issue and a challenging scientific endeavor. There is international agreement that geological storage of nuclear waste is the most promising method to ensure long-term security (IAEA, 2011a). Strategies for finding suitable geological formations to store nuclear waste differ between various coun- tries and implementers tasked with finding suitable sites for a waste repository. Here we focus on the site selection procedure in Germany.

The history of site selection for a repository for spent nuclear fuel in Germany is not new and was shaped for decades by investigations of the Gorleben salt dome accompanied by discussions and protests. After the Fukushima accident in 2011 the German government decided to phase out nuclear power, and the site selection process was redeveloped (BGE, 2021a). The site selection procedure restarted in the year 2017 from a blank map of Germany and was initiated after the adoption of the law regulating site selection in Germany, the Repository Site Selection Act (StandAG, 2017, updated 2020). The aim is to identify the area for the long-term storage of nuclear waste in the subsurface with the best possible safety over a time span of 1 million years. The Federal Company for Radioactive Waste Disposal (BGE) serves as the German waste management organization and is responsible for finding the best site. The overall political responsibility and the technical supervision lie with the Federal Ministry for the Environment, Nature Conservation and Nuclear Safety (BMU). The Federal Office for the Safety of Nuclear Waste Management (BASE) exercises legal supervision and is responsible for public participation. Public participation and transparency play an important role in the site selection (Section 1 para. 2 StandAG). Therefore, the National Citizens' Oversight Committee (NBG) supports the procedure.

In this study, first a brief summary of the German site selection procedure and the results of the first step are provided. The focus is on the methodology for the current step of the site selection procedure, which includes representative preliminary safety analyses of suitable sub-areas. 


\section{Overview of the site selection procedure}

The framework for the site selection procedure is regulated by the Repository Site Selection Act (StandAG). The site selection procedure for a repository for high-level radioactive waste in Germany comprises three phases. The phases proceed with an increasing level of detail over a progressively smaller number of potential regions and total area until the proposal of the best possible site at the end of the third phase. After the identification of sub-areas and subsequently siting regions for surface exploration in Phase I, Phase II consists of the surface exploration of the selected regions and the proposal of suitable sites for underground exploration. Underground exploration and the proposal of possible repository sites follow in Phase III. This final site decision is intended for the year 2031 (Section 1 para. 5 StandAG). See Fig. 1 for an overview of the three phases.

The first phase consists of two steps: i.e., the identification of the sub-areas (Step 1) and the identification of siting regions for surface exploration (Step 2). The first step was completed in September 2020 and is very briefly summarized in the following section.

\section{Summary of Phase I, Step 1: from a blank map to the selection of sub-areas}

The site selection procedure started with a blank map and did not a priori specify any areas that should be included or excluded from the search. The objective of the first step of the first phase was to determine sub-areas that give reason to expect favorable geological conditions for the safe disposal of high-level radioactive waste in the three considered host rocks (rock salt - halite, claystone, and crystalline rock) by applying legally defined exclusion criteria, minimum requirements, and geoscientific weighing criteria (Section 13 StandAG). This step resulted in the selection of 90 sub-areas that cover an area equivalent to approximately $54 \%$ of the onshore area of Germany (Fig. 2). The results were published in the Sub-areas Interim Report pursuant to Section 13 StandAG in September 2020 (BGE, 2020a).

The exclusion criteria pursuant to Section 22 StandAG are (1) large-scale vertical motion of the land surface, (2) proximity to active fault zones, (3) influence of present or past mining or drilling activity, (4) seismic activity, (5) volcanic activity, and (6) the presence of young groundwater. These criteria were used to exclude areas where any of the six processes could be attested. After the exclusion criteria were applied, the remaining area was investigated by means of minimum requirements (Section 23 StandAG): (1) effective hydraulic conductivity, (2) thickness, (3) depth, (4) area, and (5) long-term barrier integrity. If one of the five abovelisted requirements cannot be fulfilled, the area is not suitable to host a repository and is hence excluded from the search. After the exclusion criteria and minimum require- ments were applied, the remaining areas were evaluated by means of 11 geoscientific weighing criteria, which are defined in the annexes to Section 24 of the Repository Site Selection Act (StandAG) and assess the (1) transportation of radioactive substances by groundwater movement, (2) configuration of the rock bodies, (3) ability of spatial characterization, (4) long-term stability of favorable conditions, (5) favorable rock mechanical properties, (6) tendency to form fluid flow paths, (7) gas formation, (8) temperature tolerance, (9) retention capacity, (10) hydrochemical conditions, and (11) protection by the overburden. Minimum requirements and geoscientific weighing criteria evaluate the containment-providing rock zone, which is part of the rock that ensures safe containment of the radioactive waste in a repository that is mainly based on geological barriers in interaction with technical and geotechnical barriers (Section 2 no. 9 StandAG). The spatial extent of the containmentproviding rock zone is to be derived by model calculations during the preliminary safety assessments and as result of the upcoming explorations beginning in Phase II of the site selection procedure. Until the spatial dimension has been specified, the evaluation refers to a rock formation that would be able to accommodate the containment-providing rock zone.

The application of the geoscientific weighing criteria led to the identification of sub-areas where favorable geological conditions can be expected for the safe final disposal of radioactive waste. The presence of favorable geological conditions was evaluated during a comparative process of verbal argumentation during which the evaluation of all 11 criteria was discussed by a group of BGE experts. Thereby, a negative rating of a single weighing criterion was not sufficient to exclude an area, in contrast to the application of the exclusion criteria and minimum requirements.

The site selection procedure is supported by a large amount of existing geoscientific data. In Phase I of the site selection procedure, all results are solely based on existing data provided by federal and state geological surveys and other agencies such as the Federal Institute for Geosciences and Natural Resources (BGR). New geoscientific data will be added by specific exploration once Phase II and Phase III of the site selection start. In Phase II surface exploration, including seismic surveys and drilling of boreholes, and in Phase III subsurface exploration, possibly including the excavation of an exploratory mine, are part of the siting process. Related to the Repository Site Selection Act (StandAG), another law, the Geological Data Act (GeolDG, 2020), was adopted in Germany in the year 2020. This law regulates the state geological survey and the transmission, permanent safeguarding, and public availability of geological data as well as the availability of geological data for the fulfillment of public tasks such as the site selection procedure (Section 1 GeolDG). It thus makes an important contribution to the principle of transparency of the process. 


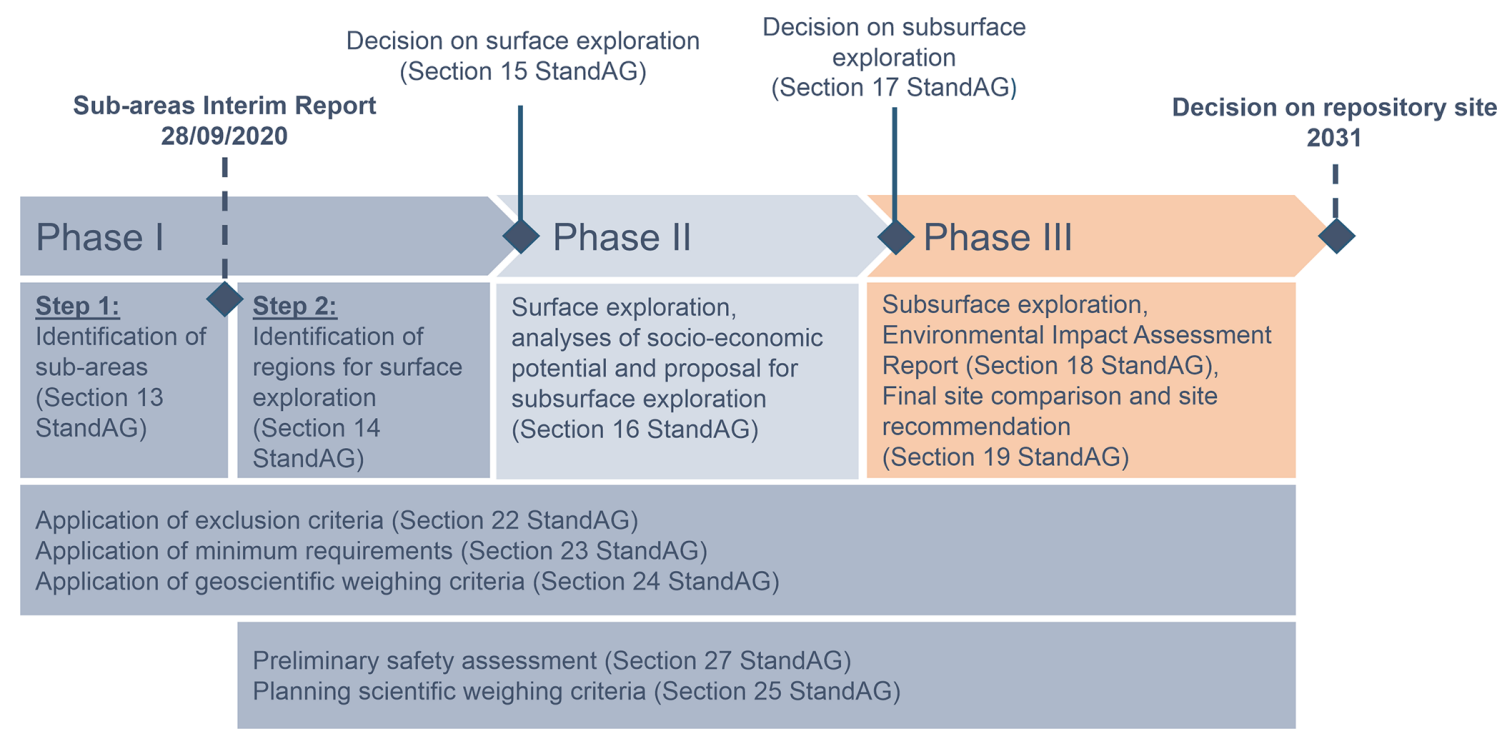

Figure 1. Schematic overview of the three phases of the site selection procedure in Germany according to the Repository Site Selection Act (BGE, 2020a).

\section{Analyzing the safety of the disposal system by means of representative preliminary safety analyses (Phase I, Step 2)}

The second step of Phase I of the site selection procedure commenced after the submission of the Sub-areas Interim Report in 2020 and comprises the identification of siting regions (Section 14 StandAG). For this, representative preliminary safety analyses are performed. Furthermore, geoscientific weighing criteria are applied again and planningscientific weighing criteria are applied for the first time considering the stipulations in Section 25 of the Repository Site Selection Act (StandAG). Here, the focus is on the methodology of the representative preliminary safety analyses by presenting the regulatory guidelines and a first insight on how these guidelines are planned to be implemented in practice. Note that the implementation of the safety analyses is at an early stage, and the implementations presented here may still be subject to numerous changes. However, the aim is to provide a document that can be used as a base for further discussion with the scientific community, stakeholders, and the general public.

Preliminary safety analyses are an important instrument within the site selection procedure. These analyses will be carried out three times in total with an increasing level of detail over time (Phase I: representative preliminary safety analyses, Phase II: further-developed preliminary safety analyses, Phase III: comprehensive preliminary safety analyses). The safety analyses serve to assess "the extent to which the safe containment of radioactive waste can be expected by exploiting the geological site conditions at the site" (Section 27 para. 1 StandAG). The requirements for conducting preliminary safety analyses in the site selection proce- dure are defined by Section 27 of the Repository Site Selection Act (StandAG) and a governmental directive, the Ordinance on Requirements for Conducting Preliminary Safety Analyses in the Site Selection Procedure for the Disposal of High-Level Radioactive Waste (Disposal Safety Analysis Ordinance - EndlSiUntV, 2020). Safety requirements for disposal based on safety principles defined by Section 26 of the Repository Site Selection Act (StandAG) are laid down in the Ordinance on Safety Requirements for the Disposal of HighLevel Radioactive Waste (Disposal Safety Requirements Ordinance - EndlSiAnfV, 2020). Figure 3 illustrates the content of the representative preliminary safety analyses according to the Disposal Safety Analysis Ordinance (EndlSiUntV).

Representative preliminary safety analyses commence with the identification of one or more investigation areas for each of the sub-areas defined in Phase I, Step 1 (see Sect. 3). The suitability as a potential repository is investigated for each of these investigation areas. Each sub-area must contain at least one investigation area but may also contain several investigation areas in the case of overlapping host rocks or the investigation of different preliminary safety concepts in one sub-area (Section 3 EndlSiUntV). The inventory of the high-level nuclear waste that will be stored in the repository has to be compiled, including information on the quantity, type, composition, and activity of the radioactive waste (Section 4 para. 2 EndlSiUntV). All steps of preliminary safety analyses described in the following (Sections 5 to 12 EndlSiUntV) have to be performed for each previously defined investigation area (Section 4 para. 1 EndlSiUntV).

A geosynthesis will be prepared for each investigation area. The geosynthesis is a compilation and interpretation of all geoscientific information relevant to the safety of a poten- 


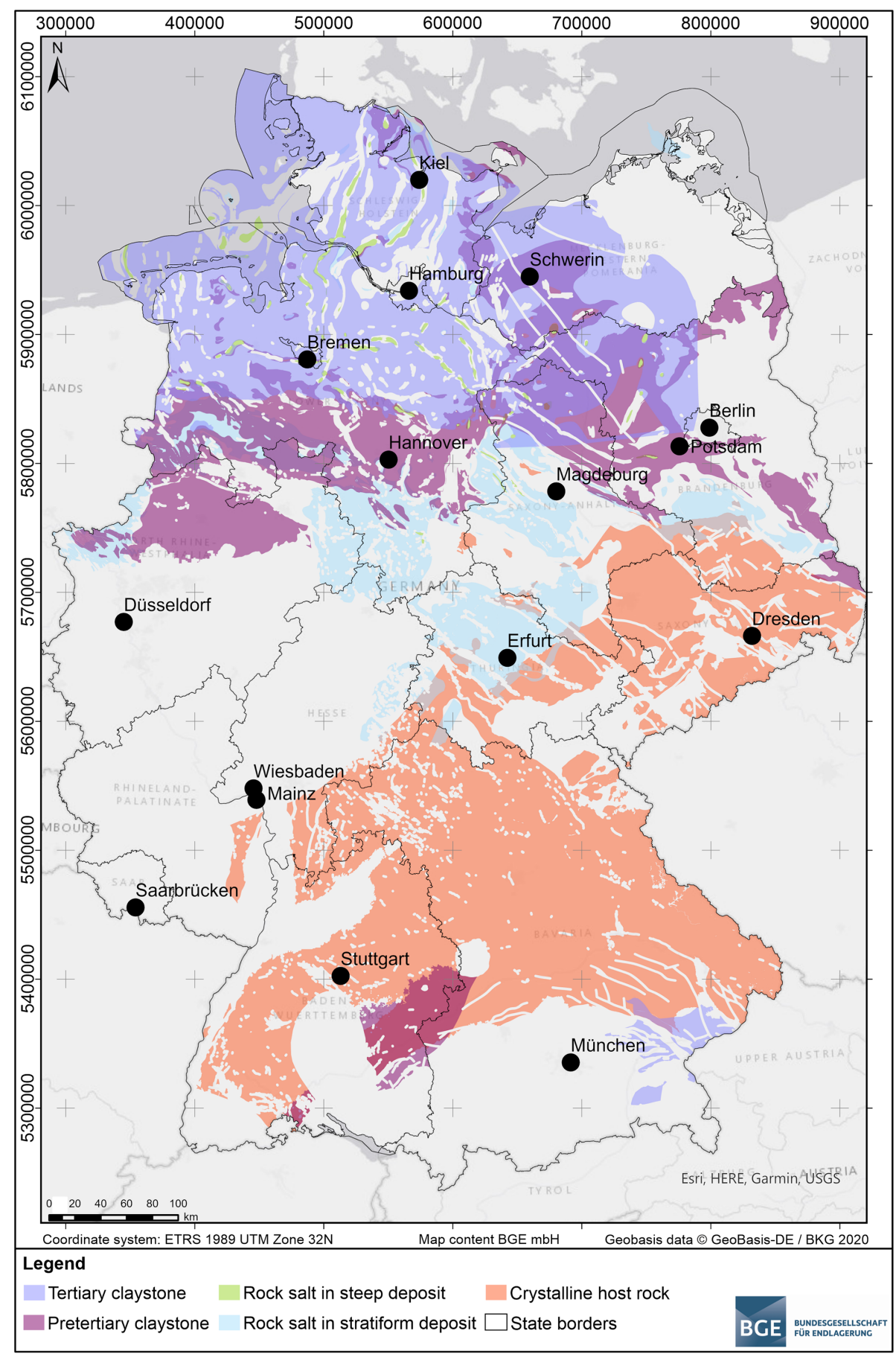

Figure 2. Map view of the sub-areas that were selected in Phase I, Step 1 of the site selection procedure (modified after BGE, 2020b).

tial repository and forms one pillar of the subsequent analyses (Section 5 EndlSiUntV).

The safety strategy in terms of how the safe storage of the radioactive waste will be maintained across all operational phases of the repository, from its construction to the end of the assessment period of 1 million years, is described in a preliminary safety concept (Section 6 EndlSiUntV, Sec- tion 10 EndlSiAnfV). The waste has to be concentrated in the disposal system in the assessment period passively and maintenance-free through a robust, graded system of multiple barriers with different safety functions (Section 4 EndlSiAnfV). The safety concept includes, among other things, a description of all intended geological and technical barriers and states their safety functions as well as their interactions. 


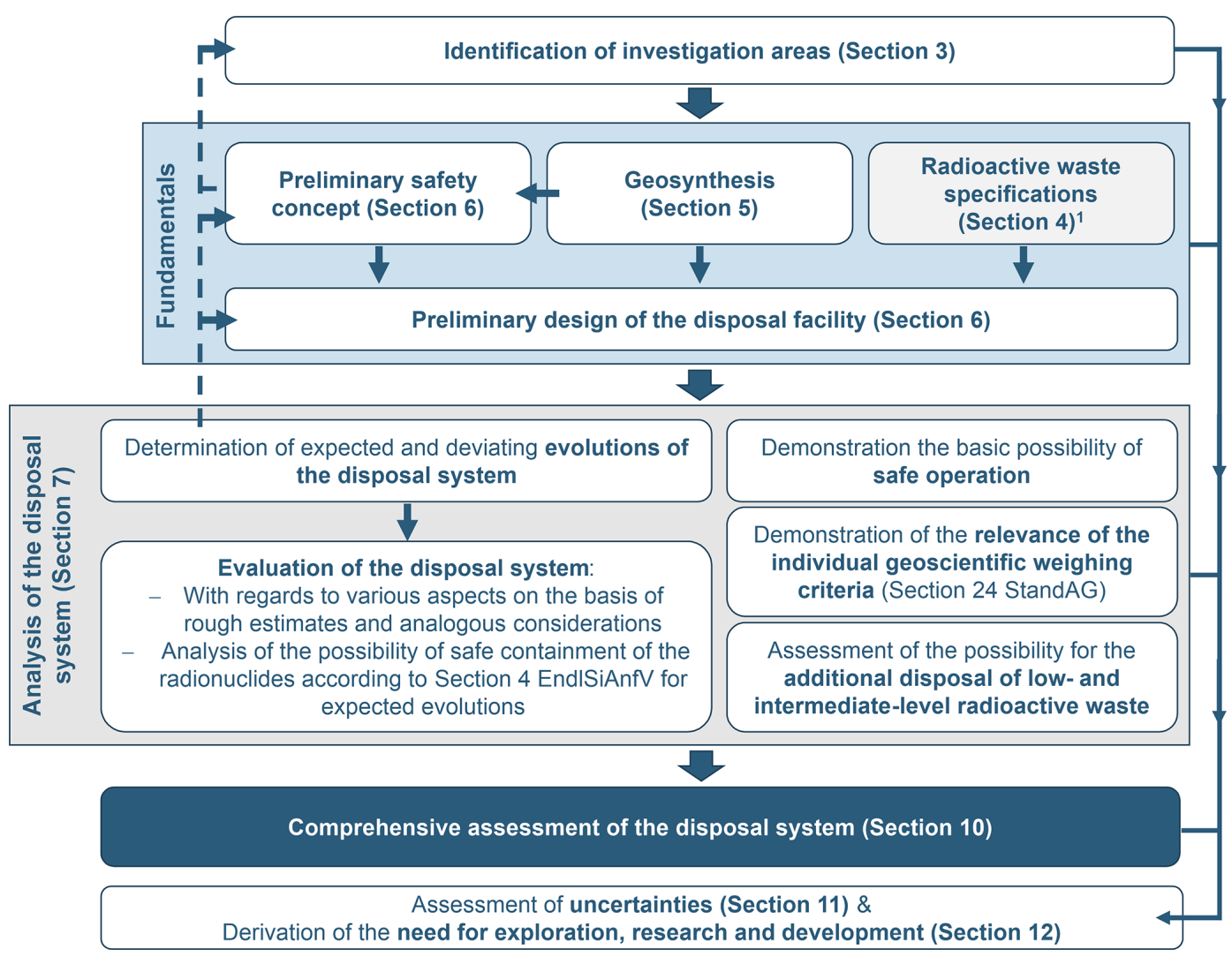

Figure 3. Schematic illustration of the content of the representative preliminary safety analyses according to the Disposal Safety Analysis Ordinance (EndlSiUntV). ${ }^{1}$ The radioactive waste specifications can be compiled once, whereas all other steps of the preliminary safety analyses have to be carried out for each investigation area.

Engineered technical barriers of the repository system are, for example, the fuel matrix and the canister into which the radioactive waste is placed. Additional engineered barriers, such as a buffer that is placed around the canister and materials used to reseal the area of emplacement and the shafts, utilize geological materials like bentonite and are hence termed geotechnical barriers. The essential barrier, which ensures the safe containment of the waste in such a way that the radionuclides remain largely at the place of their original emplacement, is either one or more containment-providing rock zones within the host rock. In the case that no containmentproviding rock zone can be identified, the essential barrier is formed by a combination of technical and geotechnical barriers (this second case is only applicable for crystalline host rocks; compare Section 4 EndlSiAnfV).

Subsequently, for each investigation area a preliminary design of the repository will be developed based on the preliminary safety concept as well as the waste specifications and the geological conditions at the investigation area. This includes, in a simplified form, a description of the essential barriers and their properties, the dimensions of a possible repository, the planned method of emplacement, measures to ensure the retrievability of emplaced disposal canisters, an overview of potential sealing and backfilling measures, and measures to protect the barriers from damage during the exploration, construction, operation, and decommissioning phases (Section 6 EndlSiUntV).

All tasks described above provide the basis for the analysis of the disposal system (Section 7 EndlSiUntV). Within this analysis, the behavior of the disposal system is investigated in its entirety, across all operational phases of the repository and under consideration of possible future evolutions of the disposal system with regard to the safe containment of the radioactive waste and its robustness. Therefore, the following aspects have to be evaluated for the assessment period (Section 7 EndlSiUntV):

- the possibility of spatial characterization of the disposal system,

- the long-term stability of the geological conditions,

- the thermal conditions in the disposal system,

- the area requirements for the realization of the disposal mine,

- the possibility of designating a containment-providing rock zone, and, 
- for the expected evolutions, the possibility of safe containment of the radionuclides by interaction of different safety functions within the essential barriers.

The analysis of the disposal system in the representative preliminary safety analyses can be performed based on rough estimates and analogous considerations. The abovementioned aspects have to be evaluated in the representative preliminary safety analyses, whereas a detailed long-term safety analysis (Section 9 EndlSiUntV) is part of the preliminary safety analyses conducted during Phase II and Phase III of the site selection procedure.

As part of the analysis of the disposal system, the longterm evolution of the repository is regarded by evaluating different possible future evolutions of the disposal system (Section 7 EndlSiUntV). The aim is an estimation of the effects of possible future developments on the safety of the waste repository. This includes, for example, long-term geological evolutions such as glacial cycles or transgression and the impact of the related erosion processes on the safety of the repository. The assessment is both qualitative and, where possible, quantitative using numerical models of the transport of radionuclides in the subsurface around potential nuclear waste repositories. The quantitative assessments include an evaluation of the effects of uncertainties in the data and modeled processes. The developments of the repository are classified (in decreasing likelihood of occurrence and relevance to safety optimization) as expected evolutions, deviating evolutions, hypothetical evolutions, and evolutions based on future human activities (Section 3 EndlSiAnfV). This classification of developments is intended to be qualitative. For the representative preliminary safety analyses only the expected and deviating evolutions have to be considered; the other developments will be taken into account in Phase II and Phase III of the site selection procedure. An additional simplification in the representative preliminary safety analyses stipulated by Section 7 of the Disposal Safety Analysis Ordinance (EndlSiUntV) is the assumption that all technical and geotechnical barriers fulfill their safety functions as intended. Hence, the focus in this current stage is on the comparative safety of geological settings and on the geological processes.

To that end, the utilization of the internationally accepted FEP (features, events, and processes) catalog and scenario methodology is intended (IAEA, 2011b; OECD Nuclear Energy Agency, 2000; Capouet et al., 2019). Note that here scenario development is termed as future evolutions (scenarios) of the nuclear waste repository. A common FEP catalog will be created for all host rocks and all preliminary repository concepts. Through screening, this common catalog will yield a specific FEP catalog for each investigation area. A database will be set up to manage information on all FEPs, documentation of the identified interactions between features and processes, and the decisions taken by experts in the screening process. Subsequently, the expected and deviating future evo- lutions of the disposal system and its geological setting can be systematically derived from the FEP catalog.

The analysis of the disposal system will be supported by a suite of numerical models that will be used to provide quantitative estimates of the transport of radionuclides in the subsurface. The primary objective of the numerical models is to evaluate whether it can be ensured that no more than a fraction equal to $10^{-4}$ of the mass and number of atoms of the initially stored radionuclides escapes the essential barriers over the course of 1 million years across all the expected evolutions of the repository. In addition, the fraction that escapes annually should not exceed $10^{-9}$. These limits are stipulated in Section 4 of the Disposal Safety Requirements Ordinance (EndlSiAnfV). The limits for the fraction that escapes include the radioactive decay products of the stored nuclear waste. The model assessments will be performed for representative $1 \mathrm{D}, 2 \mathrm{D}$, and $3 \mathrm{D}$ sections of each of the investigation areas that will be selected in the first step of the representative preliminary safety analyses. A limited number of full 3D model runs will be combined with a larger set of model runs in two spatial dimensions or one spatial dimension. The aim of the suite of model experiments is to cover the variability in radionuclide transport governed by the geological structure of the subsurface and the variability induced by the variability of hydrogeological parameters as well as the range of expected future evolutions. Currently, models with different complexity to explore their (often datadriven) limitations and benefits are being evaluated. At this early stage of the site selection procedure, the aim is to develop models that include dominant physical processes, but with a comparatively low degree of complexity compared to the later phases of the site selection procedure.

Since transparency and public participation are key elements of the site selection procedure (see Section 1 StandAG), the numerical model analyses will use primarily open-source model codes, especially OpenGeoSys (Bilke et al., 2019; Kolditz et al., 2012). BGE and partner organizations will contribute to further developing this code. In addition, the aim is to publish the model input and output data on open-access online platforms to ensure a transparent and reproducible workflow. However, during the early phase of the site selection procedure well-established closed source codes like FEFLOW (Diersch, 2014) will also be used.

In addition to the aspects of long-term safety of the disposal system described above, the analysis of the disposal system (Section 7 EndlSiUntV) also entails the assessment of the basic possibility of safe operation of the repository. A detailed operational safety analysis will be the subject of the preliminary safety analyses following in Phase II and Phase III of the site selection procedure (Section 8 EndlSiUntV). Furthermore, the volume of host rock that is available will be evaluated to investigate the possibility of an additional disposal of larger quantities of lowand intermediate-level radioactive waste. It is also necessary to assess the relevance of each geoscientific weighing crite- 
rion (Section 24 StandAG). The findings of this assessment will be used in the renewed application of the geoscientific weighing criteria that will be carried out subsequently to the representative preliminary safety analyses.

The findings of the analysis of the disposal system will be summarized in a comprehensive assessment of the repository system (Section 10 EndlSiUntV). Based on the results of the analysis of the disposal system, the safety of the disposal system by means of the safe containment of the radioactive waste and its robustness have to be assessed. In addition to the comprehensive assessment of the repository system, the representative preliminary safety analyses also include an uncertainty analysis and an assessment of the consequences of these uncertainties for the safety of the repository (Section 11 EndlSiUntV). Given the importance of these uncertainties, these analyses will be integrated in all previous work steps and will be reviewed and analyzed during this step. Since data availability in Phase I of the site selection procedure is limited in both number and spatial distribution and analyses are carried out solely on existing data, uncertainties are high. However, one key aspect in the site selection procedure is that all areas are treated equally regardless of the data availability, and hence high uncertainties are no reason for exclusion. Based on this, an assessment will be made regarding to what extent additional exploration and research work can possibly reduce the existing uncertainties in the next phases. This leads to the last aspect of the representative preliminary safety analyses, which is the identification of the exploration, research, and development needs for the next phases of the site selection (Section 12 EndlSiUntV).

As described above a large amount of work has to be carried out in the current Step 2 of Phase I of the site selection procedure. Since all listed steps of the representative preliminary safety analyses have to be performed for each previously defined investigation area, this results in at least 90 analyses, one for each sub-area determined in Step 1 of Phase I. Hence, a methodology has to be developed that allows for a comparable and robust application of the representative preliminary safety analyses to all investigation areas and the analyses with a reasonable level of detail within a reasonable time frame. Since geological data availability in this early phase of the site selection procedure is generally low and heterogeneous, the level of detail of the analyses has to adapt to this level. However, it still has to enable comparison and distinction between the investigation areas.

The current approach is to develop the methodology utilizing practical examples taking into account the area-specific data availability. Therefore, four sub-areas, one in each host rock and in the case of rock salt different host rock configurations (steep and stratiform deposit), were chosen (BGE, 2021b, c, d, e) for the first application of the representative preliminary safety analyses. Based on the work for these areas the final methodology for the conduction of the representative preliminary safety analyses is derived and afterwards transferred to the remaining areas. The intention is that thereby only minor adjustments will have to be made for certain steps of the representative preliminary safety analyses (see above), resulting in an overall manageable workload. This applies, for example, to the design of the repository: once a design is established for one of the areas utilized for the methodology development, ideally only modifications of the design like adjustment to the area-specific depth and thickness of the host rock have to be made later on. However, other steps like geosynthesis require an area-specific handling, resulting in corresponding time and resource efforts. Another challenge that comes with the large number of analyses is transparent, easily understandable documentation. To achieve this, utilizing databases wherever possible is planned, for example for the determination of the possible future evolutions of the repository system (FEP catalog and scenario methodology). The intention is to discuss the developed methodology with the public in spring 2022.

\section{Summary and conclusions}

The site selection procedure for the deep geological storage of radioactive waste in Germany is challenging given that it is a procedure that considers a range of three different potentially suitable host rocks: rock salt, claystone, and crystalline rock. The procedure started with a blank map and proceeds in three phases with an increasing level of detail and a shift from the use of already available geological data to active surface and subsurface exploration. The first and all subsequent steps are supported by a large compilation of geoscientific data; additionally, data transparency (i.e., public access) is an essential part of the process.

The first step of the first phase resulted in the identification of 90 potentially suitable sub-areas that cover an area equivalent to approximately $54 \%$ of the onshore area of Germany. The procedure is currently at Step 2 of Phase I and includes representative preliminary safety analyses, for which the workflow and first ideas for its implementation were described here. The representative preliminary safety analyses follow the guidelines of the Disposal Safety Requirements Ordinance (EndlSiAnfV) and the Disposal Safety Analysis Ordinance (EndlSiUntV). The analyses consist of a series of work steps that combine a preliminary safety concept and preliminary design of the repository, the analysis of geological conditions, an assessment of potential future developments, and an evaluation of the implications for the longterm safety of the repository, which will be supported by numerical models of radionuclide transport in the subsurface. The result of the representative preliminary safety analyses will be a set of potential regions, to which the geoscientific weighing criteria will be applied again. The work plan here was published relatively early in the process and may still be subject to numerous changes. However, we hope that the discussion of the preliminary plan for the current phase of the site selection procedure here boosts communication and 
discussion with the scientific community, stakeholders, and the general public. The procedure outlined here will be specified in more detail in future publications when the individual work steps have been carried out.

Data availability. The geoscientific data used for Step 1 of Phase II are documented in the Sub-areas Interim Report pursuant to Section 13 StandAG and in the subsequent reports. After categorizing the data according to the GeolDG, the data are made available to the public if legally permitted. In cases in which, e.g., third-party rights to the data exist, the data may not be made public yet. Please visit our home page at http://www.bge.de to view and retrieve the data. As the site selection procedure commences more and more data will be made public.

Author contributions. EMH was responsible for conceptualization, writing, and review. EL, PM, PK, FP, and DG were responsible for writing. WR was responsible for conceptualization, writing, review, and supervision.

Competing interests. The contact author has declared that neither they nor their co-authors have any competing interests.

Disclaimer. Publisher's note: Copernicus Publications remains neutral with regard to jurisdictional claims in published maps and institutional affiliations.

Special issue statement. This article is part of the special issue "European Geosciences Union General Assembly 2021, EGU Division Energy, Resources \& Environment (ERE)". It is a result of the EGU General Assembly 2021, 19-30 April 2021.

Acknowledgements. Too many colleagues have contributed and will contribute in the process of nuclear waste site selection to be named here as authors. However, their contributions are most important and valued.

Review statement. This paper was edited by Michael Kühn and reviewed by two anonymous referees.

\section{References}

BGE: Sub-areas Interim Report pursuant to Section 13 StandAG, 436 pp., available at: https://www.bge.de/fileadmin/user_upload/ Standortsuche/Wesentliche_Unterlagen/Zwischenbericht_ Teilgebiete/Zwischenbericht_Teilgebiete_-_Englische_ Fassung_barrierefrei.pdf (last access: 30 August 2021), 2020a.

BGE: Sub-areas pursuant to $\S 13$ Site Selcetion Act (StandAG), available at: https://www.bge.de/fileadmin/user_upload/ Standortsuche/Wesentliche_Unterlagen/Zwischenbericht_
Teilgebiete/20210630_Karte_UEbersichtskarte_Teilgebiete_ DIN_A4_farblich_hinterlegt_englisch_.jpg (last access: 30 August 2021), 2020b.

BGE: History of the search for repositories, available at: https://www.bge.de/en/sitesearch/ history-of-the-search-for-a-repository/ (last access: $30 \mathrm{Au}-$ gust 2021), 2021a.

BGE: Steckbrief für ein Gebiet zur Methodenentwicklung Gebiet zur Methodenentwicklung: Opalinuston, 3 pp., available at: https://www.bge.de/fileadmin/user_upload/Standortsuche/ Wesentliche_Unterlagen/Methodik/Phase_I_Schritt_2/04_ Steckbrief_Gebiet_zur_Methodenentwicklung_Opalinuston_ TG_001_00_barrierefrei.pdf (last access: 30 August 2021), $2021 b$.

BGE: Steckbrief für ein Gebiet zur Methodenentwicklung - Gebiet zur Methodenentwicklung: Salzstock Bahlburg, 2 pp., available at: https://www.bge.de/fileadmin/user_upload/Standortsuche/ Wesentliche_Unterlagen/Methodik/Phase_I_Schritt_2/01_ Steckbrief_Gebiet_zur_Methodenentwicklung_Bahlburg_TG_ 035_00_barrierefrei.pdf (last access: 30 August 2021), 2021c.

BGE: Steckbrief für ein Gebiet zur Methodenentwicklung - Gebiet zur Methodenentwicklung: Saxothuringikum, 2 pp., available at: https://www.bge.de/fileadmin/user_upload/ Standortsuche/Wesentliche_Unterlagen/Methodik/Phase_I_ Schritt_2/03_Steckbriefe_Gebiete_zur_Methodenentwicklung_ Saxothuringikum_TG_009_00_REV01_barrierefrei.pdf (last access: 30 August 2021), 2021d.

BGE: Steckbrief für ein Gebiet zur Methodenentwicklung - Gebiet zur Methodenentwicklung: Thüringer Becken, 3 pp., available at: https://www.bge.de/fileadmin/user_upload/ Standortsuche/Wesentliche_Unterlagen/Methodik/Phase_I_ Schritt_2/02_Steckbrief_Gebiet_zur_Methodenentwicklung_ Thueringer_Becken_TG_078_02_barrierefrei.pdf (last access: 30 August 2021), 2021e.

Bilke, L., Flemisch, B., Kalbacher, T., Kolditz, O., Helmig, R., and Nagel, T.: Development of Open-Source Porous Media Simulators: Principles and Experiences, Transport Porous Med., 130, 337-361, https://doi.org/10.1007/s11242-019-01310-1, 2019.

Capouet, M., Carter, A., and Ciambrella, M.: International Features, Events and Processes (IFEP) List for the Deep Geological Disposal of Radioactive Waste. Version 3.0, Organisation for Economic Co-Operation and Development, Paris, 2019.

Diersch, H.-J. G.: FEFLOW - Finite Element Modeling of Flow, Mass and Heat Transport in Porous and Fractured Media, Springer, Berlin, Heidelberg, Berlin, Germany, 996 pp., https://doi.org/10.1007/978-3-642-38739-5, 2014.

EndlSiAnfV: Endlagersicherheitsanforderungsverordnung vom 6 . Oktober 2020 (BGB1. I S. 2094), 2020.

EndlSiUntV: Endlagersicherheitsuntersuchungsverordnung vom 6. Oktober 2020 (BGB1. I S. 2094, 2103), 2020.

GeolDG: Geologiedatengesetz vom 19. Juni 2020 (BGB1. I S. 1387), 2020.

IAEA: Geological Disposal Facilities for Radioactive Waste, International Atomic Energy Agency, Vienna, Austria, Specific Safety Guide No. SSG-14, 124, 104 pp., 2011a.

IAEA: Disposal of Radioactive Waste, International Atomic Energy Agency, Vienna, Austria, Specific Safety Requirements No. SSR-5, 83, 62 pp., 2011 b. 
Kolditz, O., Görke, U.-J., Shao, H., and Wang, W. (Eds.): Thermohydro-mechanical-chemical processes in porous media: benchmarks and examples, Springer Science \& Business Media, Berlin, Heidelberg, 399 pp., 2012.

OECD Nuclear Energy Agency: Features, Events and Processes (FEPs) for Geologic Disposal of Radioactive Waste: An International Database, OECD Publishing, Paris, 2000.
StandAG: Standortauswahlgesetz vom 5. Mai 2017 (BGB1. I S. 1074), das zuletzt durch Artikel 1 des Gesetzes vom 7. Dezember 2020 (BGB1. I S. 2760) geändert worden ist, 2017, last updated 2020. 